\title{
Dedicated, Persistent, Knowledgeable, Visionary and Smart: Dr. Oreste Ghisalba Helped Leverage the Great Potential of Biotechnology to the Benefit of Switzerland
}

\author{
Michael Altorfer*, Dominik Escher, Adrian Härri, and Martin Howald
}

\begin{abstract}
Oreste Ghislaba's powerful vision and actions to make Switzerland a world-leading hub in biotechnology are described. He recognised the great potential for innovation in biotechnology and was able to communicate this to stakeholders in academia, industry and politics. He was instrumental in the creation of organisations such as Swiss Biotech Association, the CTI, the SATW, TA-Swiss, and the Swiss Industrial Biocatalysis Consortium that helped to create the Swiss biotech hub.
\end{abstract}

Keywords: Biotechnology · Swiss Biotech Association

When the Swiss Biotech Association ${ }^{[1]}$ was founded in 1998, Dr. Oreste Ghisalba was one of its founding members. This was neither a surprise nor a coincidence:

Ever since Oreste started his education as a lab technician in 1962, he dedicated his studies and career to science. Starting in the field of textile chemistry, he expanded his studies to physics, mathematics and later to molecular biology and microbiology.

Early on, he realized the great and broad potential biotechnology was offering to science-based industries and he set out to exploit it to the benefit of Switzerland and beyond. Over many decades he devoted his energy and his broad scientific knowhow to describe a vision in which biotechnology played a key role in scientific innovation and to implement the necessary tools to achieve it. Thereby, he was persistent, relentless, and smart in building networks, coordination committees and funding platforms aiming at strengthening the Swiss biotech academic research and talent formation. His main focus was dedicated to the effective transfer of biotech research results to innovative industrial applications by means of public/private partnerships and the formation of biotech start-up companies in Switzerland.

These efforts paid off and over a period of about six decades, Switzerland has become one of the leading biotech hubs in the world. Consistently, Switzerland is selected to be the most attractive biotech working place for international talents. In the last few years, biotech investors provided new funds in excess of 1.5 billion USD/year and an increasing number of multi-national corporations selected Switzerland as a production hub for biological drugs, peptides, biosimilars, and most recently also for cell-based therapies. Consequently, the contributions of the pharma/biotech industry steadily increased and reached close to $40 \%$ of the total Swiss exports in 2019.

\section{Clear and Powerful Vision}

Once the basic principles of molecular biology had been established, Oreste recognized the great potential biotechnology was offering in a wide range of scientific and industrial appli- cations. He realized that these new technologies could leverage the strengths of Switzerland in research, industrial processes and the development of novel technologies and therapies. He saw the opportunity that Switzerland could become a world-leading biotech hub.

Given his broad scientific knowledge, Oreste was able to understand the various applications of biotechnological processes in all science-based industries (e.g. pharmaceuticals, diagnostics, agriculture, food, environmental biotechnology, and specialty chemicals). At the same time, he was able to explain this vision to a wide range of stakeholders and to make his case convincingly in academia, the industry and within political and governmental bodies.

Thanks to his personality he was capable of gathering the necessary support: Various supporting organizations were established, funding was secured and resources provided to implement his vision how biotech innovation and international co-operation could benefit Switzerland. The implementation of this vision provided a boost of innovation during several decades and still contributes to the competitive advantage of Switzerland today.

\section{Engaging all Stakeholders}

To secure the support for his vision, Oreste worked at many levels and through a wide range of organizations:

Already during the time that Oreste worked at Ciba-Geigy, he had helped to ensure that biotechnology was one of the three topics selected by the Swiss parliament within the Swiss Priority Program (SPP) funding scheme of the SNSF.

SPP BioTech established three organizations, of which two are still operational: BATS, the Centre for Biosafety and Sustainability and the technology transfer organization Biotectra (founded 1996, now acting under the name Unitectra) with the mission to improve technology transfer in Switzerland within life sciences and to provide consulting and practical assistance to researchers connected to the SPP BioTech regarding technology transfer. Biotectra also produces various publications such as the 'Swiss Biotechnology 
Industry Guide' (now issued as the Swiss Biotech Directory by the Swiss Biotech Association) and different publications addressing the creation of spin-off companies and other topics in technology transfer.

The stakeholders within SPP BioTech realized that an active voice was needed to speak on behalf of the emerging biotech industry. Thus, SPP BioTech and Biotectra promoted the foundation of a biotech industry association. On March 12, 1998, the Swiss Biotech Association was established. Roland Bühlmann (Bühlmann Laboratories) was elected as its president and Martin Howald (BioConcept), Christophe Lamps (Ares-Serono International) and Bruno Oesch (Prionics) as additional board members. As SPP program manager Oreste was a driving force in founding this association and in his role as KTI/Innosuisse representative, he served as its vice-president from 2005-2017. The association aimed at facilitating access to talents and financing and it built valuable industry networks to stimulate the exchange of ideas and information to ensure that the industry stakeholders were well informed and connected. Most importantly, Oreste and the SBA co-founders ensured that the Swiss Biotech Association supported Switzerland's effort to foster a tight collaboration between the industry and academic partners. Thus, the new technologies could be readily available and applied for industrial use or to trigger the foundation of biotech start-up companies.

Oreste wanted to ensure that his vision was equally visible and beneficial to academia, the formation of talents, private/public partnerships and to Switzerland's international alliance partners. Thus, in the period of 1992-2015, Oreste was an active member of the Swiss Coordination Committee for Biotechnology (SKB), the 'Lateral Think Tank' and the scientific advisory board of the Swiss Academy of Engineering Sciences (SATW), as well as the Swiss Innovation Promotion Agency (CTI) and the steering committee of the national technology assessment (TA-Swiss).

Already in 2000, as coordinator of the SPP Biotech program, Oreste and Bernhard Sonnleitner submitted the report 'Nationale Koordination der Aus- und Weiterbildung in Biotechnologie' to the government and with this also laid the foundation for biotech curriculi within universities and the newly formed universities of applied sciences.

Oreste also actively supported the Swiss Biotech Report, a publication that promotes the activities of Swiss Biotech since 2005. The first issue was published by Ernst \& Young, seco/ Location Switzerland (now Switzerland Global Enterprise), KTI/ CTI (now Innosuisse), SWX Swiss Exchange (now SIX) and the Swiss Biotech Association. Oreste helped to bring new partners on board, such as biotechnet Switzerland, the Swiss National Science Foundation, the Swiss Federal Institute of Intellectual Property and scienceindustries. They all joined to create an annual display of Swiss Biotech's activities and contributions demonstrating the power and sustainable growth of this industry.

\section{Securing Political Support and Financial Resources}

Oreste was fully aware that the implementation of his vision would require significant financial resources and in many areas also political support to adjust priorities in favor of biotechnological $\mathrm{R} \& \mathrm{D}$ projects in academia and in public-private partnerships.

The SPP BioTech stimulus program ran through three consecutive phases from 1992 to 2001, investing overall more than CHF 156 million (64\% government funding, 20\% from academia, $16 \%$ from industry).

In 2001 Federal Councilor Pascal Couchepin approved the funding of six competence networks, one of which was the biotechnet Switzerland supporting the biotech activities within the universities of applied sciences and led by the FHNW Basel (now Muttenz).

As the Head of CTI Biotech (2003-2015), Oreste Ghisalba was instrumental in supporting emerging companies in this new industrial sector by providing advice, guidance and visibility and he helped to secure two major innovation enhancement programs that provided funding to advance biotechnology research and private/public partnerships in this emerging field:

From 2005-2012 the WTT (Wissens- und Technologietransfer) program of the CTI provided approx. CHF 30 mio to fund six consortia that supported the transfer of knowledge and technology from academia to industrial partners. The objective was to ensure that academic research groups understand the needs of the industry and the industrial partners recognize the know-how and collaboration and licensing opportunities academia could offer. A variety of measures was implemented to facilitate contacts and collaborations between academia and industrial partners, in particular small and mid-sized companies (SMEs). The Swiss Biotech Association was active in the application and management of the consortia 'Mittelland W6' supporting technology push and pull activities in all research areas in the Greater Zürich and Bern area.

The WTT program elapsed in 2012 but together with its academia partner biotechnet Switzerland, the SBA successfully applied to initiate the NTN (National Thematic Network) Swiss Biotech (2013-2018) - one of eight funded NTNs. The CTI funds for this program allowed building on the success of the WTT program and to continue to support a tight collaboration between academia and the Swiss biotech industry.

As member of the board Oreste supported the SBA and its partners to formulate and work-out the CTI applications as well as implement and coach technology transfer and reporting processes.

\section{Securing Sustainability and International Collaboration}

Most applications of biotechnology and biotechnological products are global in nature and benefit patients and consumers in all regions of the world. During his time at Ciba-Geigy Oreste was working in Japan and he realized the active role of Japan and other Asian countries in the application of industrial biotechnology in industry. Consequently, it was important to benchmark and to ensure the cooperation of Switzerland with nations leading in specific biotech applications. That is why Oreste and the Swiss Biotech Association established international partnerships (e.g. with Asian countries such as Japan, Korea and China) and were active in the organization of bi-national exchange and partnering meetings with Japan, Korea and Spain. As board member Oreste strongly supported the participation of the Swiss Biotech Association in international exhibitions and partnering events such as e.g. Biotechnica and BioJapan. These measures in international cooperation and negotiation were complemented by an excellent framework in Switzerland that encouraged R\&D activities in biotechnology, investments in this field and the formation of specialists to support the further growth and the international competitiveness of the Swiss biotech hub also long-term.

In 2017, almost 20 years after the foundation of the Swiss Biotech Association, Oreste stepped down from the board of the association and the association thanked him for his dedication, unwavering support and visionary leadership by granting him its honorary membership. By that time, Oreste's vision of a strong and globally connected Swiss biotech hub had become reality. As anticipated, biotechnology had become an essential part of the Swiss innovation power and grown into an industry that provides $>50$ '000 high quality jobs, strengthened Switzerland's position as a leading location for R\&D and production center, top universities and hospitals. At the same time, the stable political system, excellent infrastructure, attractive tax frameworks and a high quality of life secured Switzerland the top spot for highly skilled experts and talents in biotechnology, one of the most important success factors for this expanding industry. Oreste could proudly look back and conclude that he had been one of the key drivers in establishing a new industry and in strengthening the competi- 
tive position of Switzerland. But he remained humble and never considered his job to be completed. As much as he helped to build and grow the Swiss Biotech Association, to secure funding for the biotech hub and to encourage a tight collaboration between all the stakeholders, he only saw himself as a helping hand and a messenger. He was not seeking personal fame or glory. Instead he continued to focus on strengthening Swiss biotech companies and research groups, together with many of his friends that had shared his vision and worked with him in the Swiss Biotech Association, the CTI, the SATW, TA-Swiss, the Swiss Industrial Biocatalysis Consortium and in the numerous other organizations that helped implementing the vision of the Swiss biotech hub.

On December 4, 2018, Oreste died unexpectedly. Full of energy and still driving many innovative projects, his personal contribution came to a sudden end. But the impact of his work and dedication will be visible in the future success of the Swiss biotech hub and the many continued effects of the processes, organizations, networks and applications he had helped to establish. He will be remembered as a humble, smart and visionary accelerator of Swiss biotech R\&D and a man who has made a difference through his personality, character and sound scientific knowledge. A person that was able to build bridges and unite stakeholders to effectively secure the implementation of his vision to build a globally competitive biotech hub in Switzerland.

Received: February 23, 2020

[1] Originally, the Swiss Biotech Association was founded as the VSBU 'Vereinigung Schweizer Biotechnologie Unternehmen'. In 2003, the VSBU was renamed as 'Swiss Biotech Association'.

\section{License and Terms}

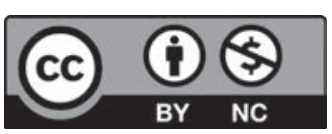

This is an Open Access article under the terms of the Creative Commons Attribution License CC BY_NC 4.0. The material may not be used for commercial purposes.

The license is subject to the CHIMIA terms and conditions: (http:// chimia.ch/component/sppagebuilder/?view=page\&id=12).

The definitive version of this article is the electronic one that can be found at doi:10.2533/chimia.2020.338
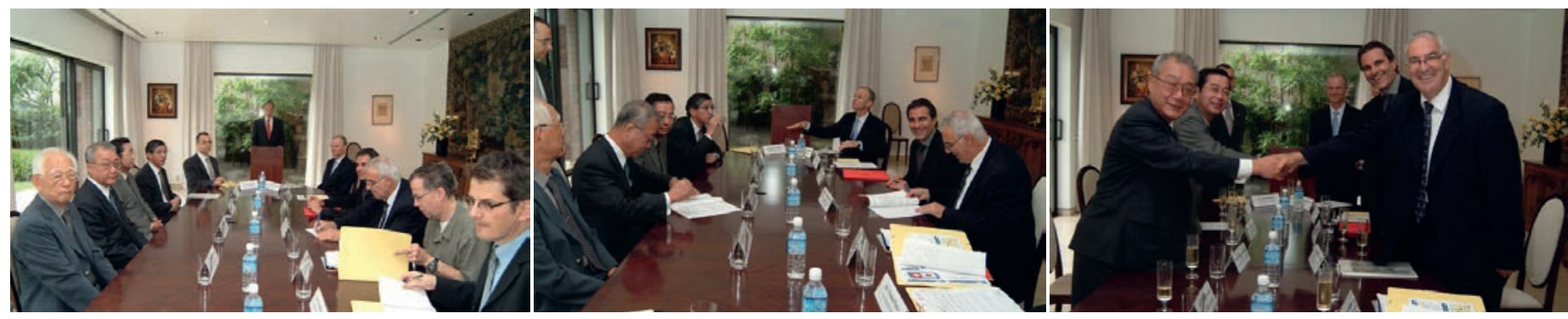

Signing of Memorandum of Understanding between SBA \& JBA, September 2006. The Swiss Ambassador in Tokyo, Jacques Reverdin invited the Japan Bioindustry Association (JBA) and the Swiss Biotech Association (SBA) - the national associations for bioindustry/biotechnology for the two countries - to his residence for the signing of the Memorandum of Understanding to develop and strengthen their informal partnership into an efficient collaboration. Left: Speech by Ambassador Reverdin ; middle: Signing of the Memorandum of Understanding; right: Congratulations.

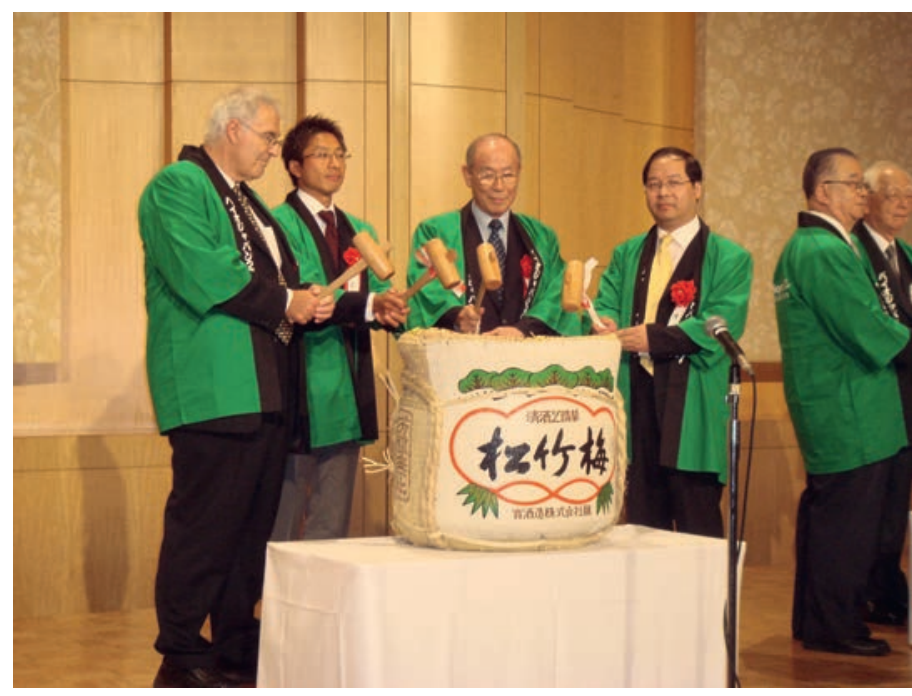

Dr. Oreste Ghisalba at Bio Japan in 2007.

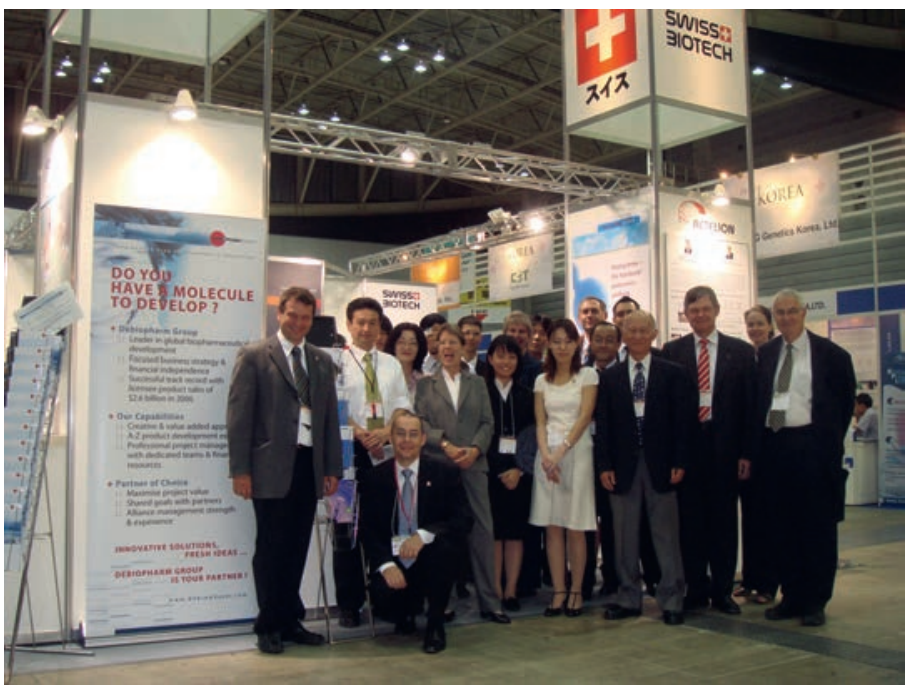

Exhibitors at the Swiss Biotech Pavilion at Bio Japan in 2007. 


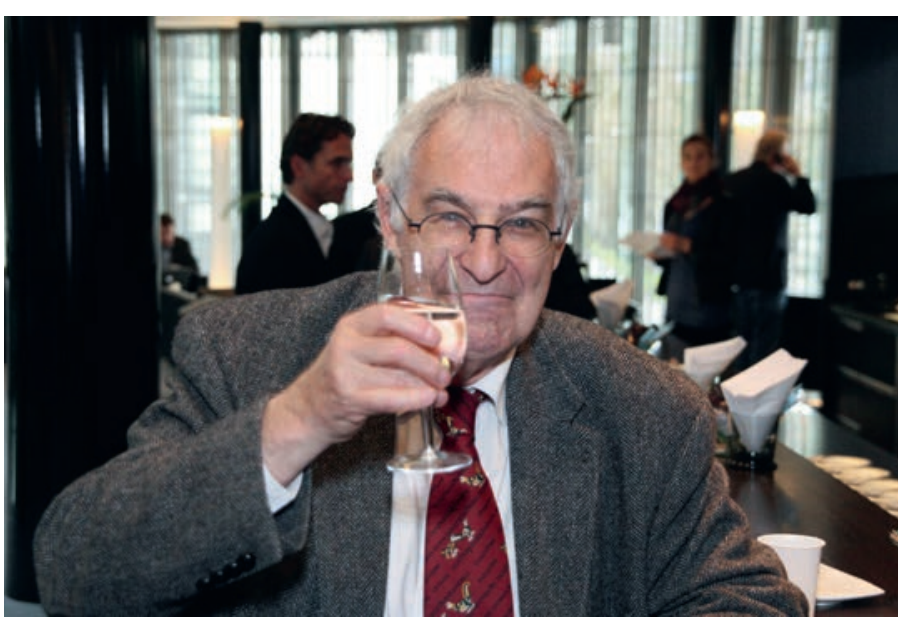

Dr. Oreste Ghisalba at the General Assembly of the Swiss Biotech Association in 2013.

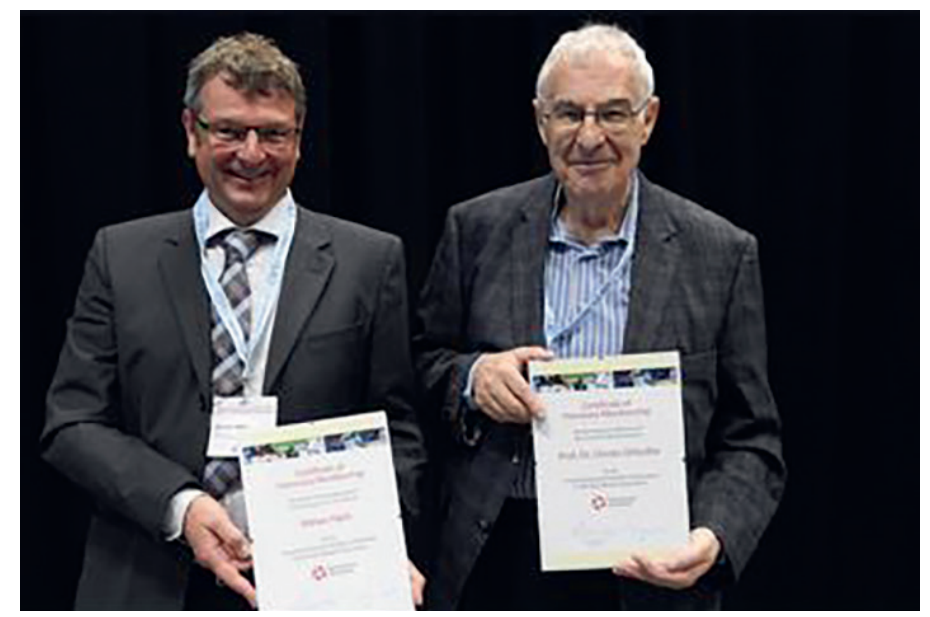

In 2017, Dr. Oreste Ghisalba (right) and Adrian Härri (left) are venerated as Honorary Members of the Swiss Biotech Association.

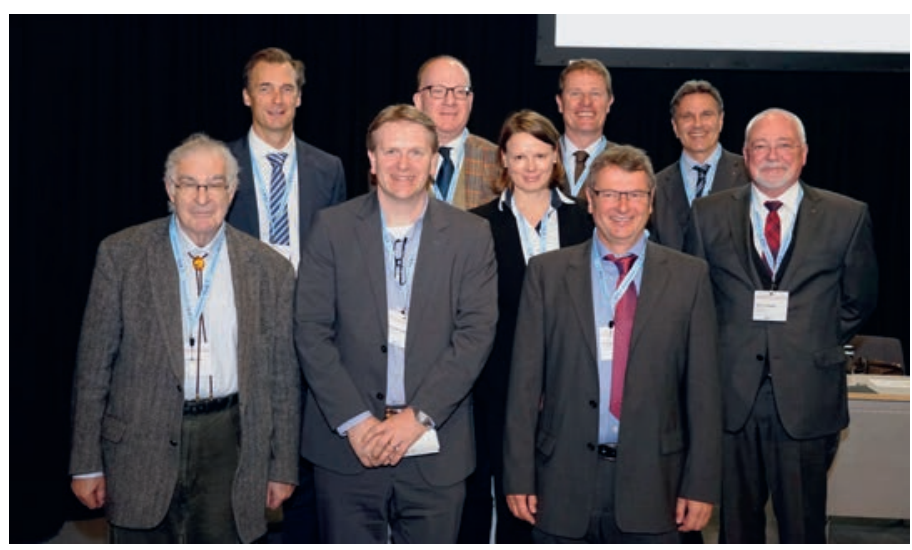

Oreste Ghisalba and the other members of the Board of Directors of the Swiss Biotech Association. From left to right: Oreste Ghisalba, Dominik Escher (president), Ulf Grawunder, Luca Bolliger, Bettina Ernst, JeanMarc Tissot, Adrian Härri, Domenico Alexakis (CEO), Martin Howald. 